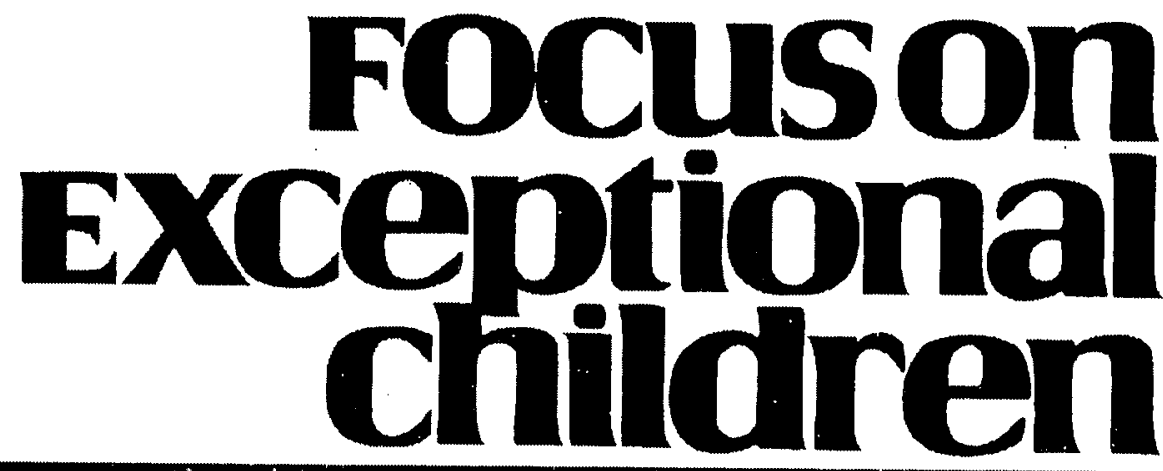

\title{
Start the Year Off Right: Designing and Evaluating a Supportive Classroom Management Plan
}

\author{
Andrea M. Capizzi
}

\begin{abstract}
A new school year brings teachers a mixture of eagerness and anxiety about the "unknown" regarding their new students. When teachers share information about students, behavioral issues are usually the first to be disclosed. It is not uncommon to hear statements such as "Oh, you have Johnny? Good luck. He's a handful," or, "Marie is a sweet girl, but she talks constantly," or even, "You have Paul? Better you than me. He never stops moving and is such a space cadet." Establishing a well-organized plan for classroom management at the outset of the year is essential for a peaceful and calm classroom that is conducive to instruction and learning for students with a variety of academic, social, and behavioral needs.
\end{abstract}

If you ask a group of teachers what they are most concerned about in their classrooms or schools, it is likely that student behavior will come up as one of the greatest-if not the greatest-issues. Managing classroom behavior can induce a teacher's anxiety (Punch \& Tuetteman, 1990; Oliver \& Reschly, 2007; Wilson, Ireton, \& Wood, 1997). New teachers rate managing behavior as one of the most challenging aspects of teaching and an area in which they feel the most unprepared (Veenman, 1984). Issues of classroom and individual student behavior often influence a teacher's decision to leave the field (Blase, 1986; Ingersoll \& Smith, 2003). Helping teachers feel confident in their classroom management skills should be an aim of teacher educators and school administrators to help retain our best teachers. This is especially important during a shortage of qualified teachers in areas of need, such as special education (McLeskey, Tyler, \& Saunders Flippin, 2004).

Many behavioral problems can be avoided by establishing a solid classroom management plan at the beginning of the school year. Although many teachers learn about basic classroom management strategies in teacher licensure programs and in-service training, a review of classwide supports and their implementation can help teachers revitalize and strengthen their classroom management plans. It is easy to become "stuck in a rut" and do what has always been done rather than to reevaluate and revise, but employing the same strategies from year to year is ineffective when student populations and needs change.

The purpose of this article is to provide an overview of several areas of classroom management that are vital for teachers and students across all areas of $\mathrm{K}-12$ education (i.e., special education, general education, physical education, art, high school, middle school, elementary school). Following a discussion of the importance of classroom management and its effect on instruction, student learning, and teacher retention, I ground the article in

Andrea Capizzi is an assistant professor in the Department of Special Education at Vanderbilt University. 
the literature supporting positive behavior supports (PBS; Sugai \& Horner, 2002) to facilitate effective classroom management that allows instruction to occur. Next, I present a worksheet for teachers to use to develop and evaluate their classroom management system. I follow up presentation of the worksheet by describing the components of classroom management detailed in the worksheet. For each component, I provide examples and suggestions for establishing or improving each component in the classroom. Each area matches a component on the worksheet and is intended to break the classwide plan into manageable segments that can be implemented feasibly by teachers and administrators who are short on time and already burdened with other tasks. Teachers and administrators rarely take the time to evaluate a management system until something goes wrong or they have a crisis with a student. This evaluation worksheet, paired with suggestions and explanations, is presented as a first step in developing an effective management system to allow teachers and administrators to start the year off on the right foot and support the wide range of students in their schools.

\section{Focuson
Exceptional
children}

ISSN 0015-511X FOCUS ON EXCEPTIONAL CHILDREN (USPS 203-360) is published monthly except June, July, and August as a service to teachers, special educators, curriculum specialists, administrators, and those concerned with the special education of exceptional children. This publication is annotated and indexed by the ERIC Clearinghouse on Handicapped and Gifted Children for publication in the monthly Current Index to Journals in Education (CIJE) and the quarterly index, Exceptional Children Education Resources (ECER). The full text of Focus on Exceptional Children is also available in the electronic versions of the Education Index. It is also available in microfilm from Serials Acquisitions, National Archive Publishing Company, P.O. Box 998, Ann Arbor, MI 48106-0998. Subscription rates: individual, $\$ 48$ per year; institutions, $\$ 66$ per year. Copyright (1) 2009, Love Publishing Company. All rights reserved. Reproduction in whole or part without written permission is prohibited. Printed in the United States of America. Periodical postage is paid at Denver, Colorado. POSTMASTER: Send address changes to:

$$
\begin{gathered}
\text { Love Publishing Company } \\
\text { Executive and Editorial Office } \\
\text { P.O. Box } 22353 \\
\text { Denver, Colorado } 80222 \\
\text { Telephone (303) } 221-7333
\end{gathered}
$$

\section{CONSULTING EDITORS} Steve Graham
Vanderbilt University

Ron Nelson University of Nebraska-Lincoln

Eva Horn

University of Kansas Publisher

\section{CLASSROOM MANAGEMENT FOR UNIVERSAL SUPPORT}

Classrooms contain students with an ever-increasing range of academic, cultural, and social backgrounds. Classrooms today have students with limited proficiency in English, disabilities, and little experience in academic environments. We ask our teachers to teach to all students, including those at risk for failure as well as those who are performing well above grade level. This, coupled with an increase in inclusion of students with disabilities in classrooms across the country, has led to some of the most diverse classrooms in our nation's history. With diversity comes diverse needs and a demand for well-managed classrooms to promote positive behavior and optimize learning and achievement (Emmer \& Stough, 2001; Sugai \& Horner, 2002). Effective management of classroom activities opens the door to teaching more academically challenging material (LePage et al., 2005).

Another reason to focus on classroom management to promote positive behavior is to create a positive learning environment. Discipline problems in schools are consistently noted as a top concern for teachers and the public (Bushaw \& Gallup, 2008) and a contributor to teacher stress and attrition (Harrell, Leavell, van Tassell, \& McKee, 2004). Helping teachers cope with the range of behavioral difficulties in the classroom is of paramount importance, given attrition rates and critical teacher shortages in areas such as special education (Connelly \& Graham, 2009).

Effective classroom management systems are vital to positive learning environments for teachers and students alike. PBS is an approach to providing a range of provisions to promote positive behavior, prevent problem behavior, and provide individualized support to those who need more focused intervention (Sugai \& Horner, 2002). The evidencebased practice of PBS has been recommended as an important strategy for dealing with challenging behavior (U.S. Department of Education, 2001). Universal supports that create safe, supportive, and effective environments are the bedrock of the PBS model (Trussell, 2008). Establishing universal supports in the classroom both encourages positive behavior and decreases problem behavior, thereby preventing many problem behaviors from occurring. A solidly conceptualized and executed classroom management plan is a universal support that sets the stage for instruction and student learning.

\section{COMPONENTS OF AN EFFECTIVE PLAN}

Much has been written about classroom management strategies, but not all strategies are created equal. With a vast literature base on classroom management, it is important to consider practices that have been documented as effective. Several authors have waded through the literature and noted evidence-based practices that should be considered for use in managing classroom behavior (Simonsen, 
Fairbanks, Briesch, Myers, \& Sugai, 2008; Simonsen, Sugai, \& Negron, 2008), whereas others have summarized information in packaged classroom management systems based on research (Cipani, 2007; Sprick, Garrison, \& Howard, 1998). These authors note the importance of including such key components as clear rules and expectations and maximizing structure. This article distills core practices necessary for a universally supportive classroom management system into six key areas that teachers and administrators can use to guide their development of new plans or evaluation of existing plans:
1. Structure
2. Classroom layout
3. Classroom décor
4. Rules
5. Routines
6. Maintaining and monitoring behavior

\section{Classwide Management Plan Appraisal Worksheet}

Classroom management plans should be tailored to fit each particular group of students and their unique needs. Since each new school year brings a new group of students, classroom management plans should be reevaluated annually and modified to suit the particular requirements of the teacher and students. Evaluating a management plan can be difficult for teachers and administrators. New teachers, whose experience may be limited to using other teachers' plans during student teaching experiences, tend to have trouble establishing their own management system. Veteran teachers sometimes see their management style as always having worked in the past and resist evaluation and change. Administrators can find it difficult to evaluate a management plan because they do not have first-hand experience with the students in a teacher's classroom and they also do not want to appear judgmental or dictatorial. A Plan Appraisal Worksheet (PAW), which is shown in Figure 1, was constructed to aid the development and review of individual classroom management systems. The PAW is designed to help teachers self-evaluate their classroom management plans and to guide them in strengthening the universal supports in their classrooms. The PAW is arranged to correspond to each of the core components of classroom management plans covered in this article. I refer to the PAW in each section and provide an overview of its use and application in the conclusion.

\section{Classroom Structure}

One of the first considerations a teacher should make when developing and evaluating a management plan is the amount of structure he or she would like to have in the classroom. Simonsen, Fairbanks, et al. (2008) define structure as "the amount of teacher or adult-directed activity, the extent to which routines are explicitly defined, and the design or physical arrangement of the classroom" (p. 353). Classroom structure can also be thought of as the level of factors a teacher chooses to leave to chance versus the level the teacher chooses to direct explicitly in the classroom. Structure sets the underlying tone in the classroom and is the basis from which the components of a management plan stem. The amount of autonomous control the teacher holds over the classroom should be individually suited to each classroom situation and group of students and is often dictated by the appropriate level of structure warranted by various classroom factors such as grade level, subject matter being taught, and academic skill level. LePage et al. (2005) note the importance of striking a balance. For example, a teacher could use a management structure to promote appropriate behavior while encouraging independent thinking and academic growth in a way that is consistent with a teacher's individual instructional goals for students.

Regardless of the theoretical basis for a teacher's management style, students tend to demonstrate more appropriate academic and social behavior in more structured classrooms (Simonsen, Fairbanks, et al., 2008). This fact alone suggests the need for some level of structure in every classroom. Not all classrooms need the same amount of structure; therefore, structure has been conceptualized according to gradations in levels. Sprick et al. (1998) identify high, medium, and low levels of structure based on student, school, and community risk lactors. Students experiencing greater intrinsic and extrinsic risk factors benefit from higher levels of structure in classrooms (Sprick et al., 1998) and more skilled classroom management (Webster-Stratton \& Taylor, 2001). Teachers should consider risk factors, not to make sweeping generalizations about certain social populations, but instead to design the most universally supportive classroom environments based on knowing their students. A cursory list of risk factors is provided in Table 1. Teachers and administrators are encouraged to consider additional situational or social risk factors particular to students in their classrooms, schools, and communities.

\section{Using the PAW: Structure}

When using the PAW, teachers complete a very brief checklist of risk factors (e.g., "More than 50\% free/ reduced lunch" and "Elementary"; see Structure in Figure 1). After completing the checklist, the teacher circles the appropriate level of structure for the classroom. A general list of the characteristics of each structure level is provided on the PAW, below the name of the level.

On the one hand, classrooms with high structure are very traditional in teacher authority and classroom layout, and free movement is rarely permitted without permission. Lowstructured classrooms, on the other hand, are characterized by more teacher-student dialogue regarding the workings of the classroom, free student movement, and open seating for students. Moderately structured classrooms fall in between. 


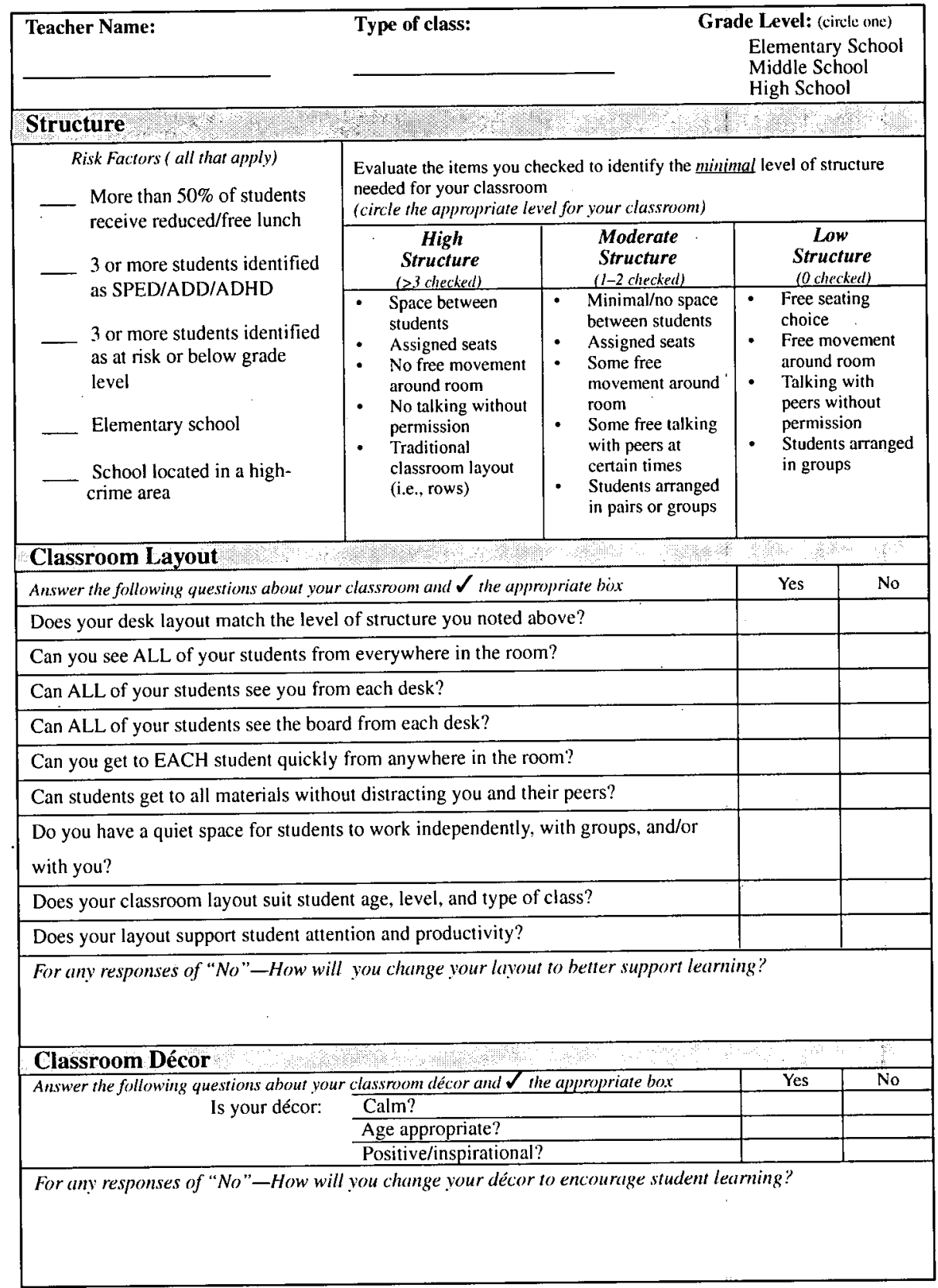

\section{FIGURE 1}

\section{Classroom Plan Appraisal Worksheet (PAW)}

The level of structure a teacher circles on the PAW corresponds to the minimal level of structure for the classroom. In general, teachers are encouraged to use higher levels of structure if they feel it best suits their students or their teaching style. If in doubt, start the year with a higher level of structure. A teacher can always lessen the level of structure as students learn routines and demonstrate appropriate behavior.

\section{Example 1-Ms. Robertson's Class}

Ms. Robertson teaches a third- and fourth-grade special education (SPED) resource class at Best View Elementary School. All of her students qualify for SPED services and are identified as having either behavioral or learning difficulties. Best View is located in an urban area and is bordered on one side by subsidized housing; $97 \%$ of the students qualify for free or reduced lunch. When Ms. Robertson 


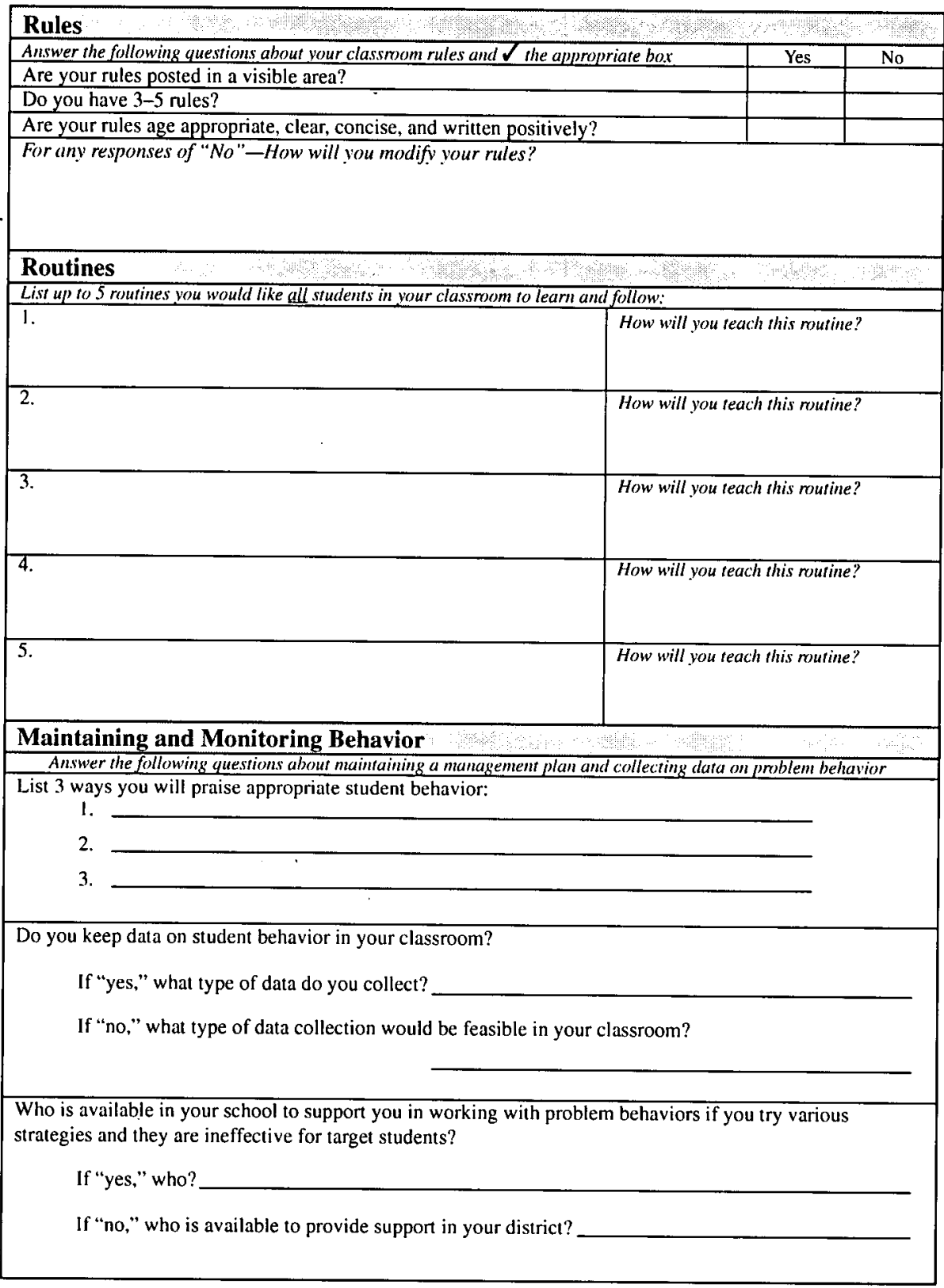

FIGURE 1 (continued)

completed the PAW, she noted all five risk factors and was not surprised to learn that her classroom needed high structure.

\section{Example 2-Mr. Matthews' Class}

Mr. Matthews teaches at H. Forrester High School. He teaches general level and Advanced Placement (AP) American History to 10 th and 11 th graders. H. Forrester is located in a suburban area, and approximately $30 \%$ of his students qualify for free or reduced lunch. He has an average of two students per class period who are identified as having ADD/ADHD in his AP classes, several students in his general classes who are reading below grade level, and several others who receive SPED services. When considering his AP classes, he noted no risk factors, and when considering his general classes, he noted two risk factors, suggesting that low structure would be an option for his AP classes and 
TABLE 1

\section{Student, School, and Community Risk Factors for Challenging Classroom Behavior}

\begin{tabular}{lll}
\hline Student-Based Factors & School-Based Factors & Community-Based Factors \\
\hline - Elementary or preschool aged & - High percentage of students & - Urban or rural \\
- Qualification for special education & qualifying for free or reduced & - High unemployment/poverty \\
or services & lunch & rate \\
- ADD/ADHD or other mental health & - High student to teacher ratio & - High crime rate, gang activity \\
diagnosis & - Highly mobile student & - Low community involvement \\
- Below grade level academic & population & or investment in education \\
performance & - Low levels of parental/family & Highly mobile community \\
- Limited proficiency in English & involvement & \\
- HLL/ESL) & \\
- History of poor attendance, office & \\
- Family factors (single-parent, incarcerated parent, foster families, etc.) & \\
- Gang involvement &
\end{tabular}

moderate structure appropriate for his general classes. Considering his personal teaching style and philosophy, Mr. Matthews decided to implement a management plan using moderate structure for all of his students. He felt comfortable with students having some free movement around the room, but he also knew that he preferred to assign students to seats. After all, even his AP students struggle with managing their loquacious social behavior, and it drives him crazy while he tries to teach. He could not imagine how much worse it would be if he let them choose their seats!

\section{Classroom Layout}

It is very interesting to visit a group of classrooms, all with the same dimensions and physical structure, and find that each room has its own individual style and feel. Teachers are very creative when arranging their spaces, and classroom arrangement can set the mood for instruction and social interactions. Finding the proper placement for teacher and student desks, bookshelves, tables, and décor can be challenging, but it is a key step in preparing a well-managed, universally supportive classroom (Trussell, 2008). Not surprisingly, the physical layout of furniture and objects in a classroom influences teacher and student behavior (Simonsen, Fairbanks et al., 2008; Stewart, Evans, Witt, \& Kaczynski, 1997). Classroom layout should reflect a teacher's philosophy on teaching and learning (Emmer \& Evertson, 2009) as well as the level of structure needed to support the needs of the students being taught.

When arranging a classroom, teachers need to consider the uses of the space and the materials needed, as well as the age and level of the students. They need to think about the activities and learning experiences that will take place in the space (Evertson, Emmer, \& Worsham, 2006). The following questions are essential for teachers to consider:

- From what part of the room do I teach the whole class?

- Do I need to plan spaces for independent work, group work, and computer stations?

- Do I need art, science, and independent study areas?

- How many student desks do I need in my room?

- Where do I like to place my desk?

Activities and the amount of time spent in a particular classroom differ, based on whether it is an elementary, middle, or high school classroom and whether it is used for general education, related arts, or special education. Care must be taken to ensure that the learning environment is set up to support the many different learning activities that occur in the space (Stewart et al., 1997). A purposeful classroom arrangement supports, rather than hinders, learning and positive behavior.

\section{Walkways}

Regardless of the level of structure best suited to a group of students, classrooms should be arranged to allow easy movement around the room. Walkways and high-traffic areas should be clear, open, and deliberately kept in mind when arranging the classroom (Evertson et al., 2006; Sprick et al., 1998; Stewart et al., 1997; Trussell, 2008). Trussell (2008) suggests bearing in mind the "bump factor" (p. 181) to make sure that students have enough space to move about the room to access materials without bumping into peers and classroom items. 


\section{Student Desks}

Desk arrangement can be a very personal choice for teachers. Desk placement can affect student productivity (Judd, 1995) and overall classroom behavior. When arranging desks, the teacher should have sufficient space to move easily throughout the room to monitor students during whole-class instruction as well as during independent and group work (Evertson et al., 2006; Sprick et al., 1998). All students should be able to see the teacher and should be visible to the teacher from all parts of the classroom. Student desks should be arranged to minimize distractions from windows, high-traffic areas, the wastebasket, and the pencil sharpener. In general, students in need of higher structure require more personal space when seated in their desks. Teachers working with students who need higher levels of structure may find that traditional rows or a horseshoe desk formation offers a more supportive learning set-up for their students. On the other hand, medium- and low-structure classrooms may run smoothly with groupings of desks in pods or "tables." At the start of the year, teachers may benefit from adopting a more structured room arrangement and then moving to a less structured arrangement as students become acclimated to classroom expectations.

\section{Using the PAW: Classroom Layout}

Teachers can evaluate their classroom layout using the PAW by responding to several yes-no questions, such as, "Does your desk layout match the level of structure you noted above?" and, "Can you see ALL of your students from everywhere in the room?" (see "Classroom Layout" in Figure 1). Teachers are encouraged to problem-solve and remedy any "no" responses in order to enhance the learning environment they have created for their students.

\section{Example 1-Ms. Kimpton's Class}

Ms. Kimpton noted that her first grade class needed moderate structure. She had to arrange her room with tables and several learning centers. Overall, she was pleased with her table placement and her carpet beside the front board so that all students could see her while she taught a lesson. After completing the PAW, she realized that she had placed her small group instruction table too close to the bathroom door, and, when seated at that table, she could not see over the bookshelf to monitor students in the independent reading center.

\section{Example 2-Mrs. Santiaga's Class}

Mrs. Santiaga teaches in a resource classroom at Justine Middle School. She teaches small resource groups of students during four periods of the day and coteaches with another teacher during one period a day. Students come and go from her classroom throughout the day if they need a quiet place to work or if they need her help with an assignment. Mrs. Santiaga knows that her students need high structure. She has arranged desks in rows for group instruction and has positioned tables for independent work. After completing the PAW, she realized that the student desks should be at the far end of the room, away from the doorway and distractions created by students who enter her room throughout the day to complete independent work.

\section{Classroom Décor}

Teachers should keep decorations in mind when setting up their classrooms. Small personal touches can add to the personality and warmth of a classroom, but they should be chosen with care. Decorations should be meaningful to the teacher and the students in the classroom. They should include items that the teacher and the students will use and enjoy and that are both age- and grade-appropriate (Evertson et al., 2006).

Occasionally, teachers overdo it when decorating their rooms. They may use excessively bright colors or too many knick-knacks, cover all wall space, and even hang items from every area of the ceiling. Overdecorating or overcrowding a classroom with personal items can make the room look and feel small (Evertson et al., 2006). It can also be highly distracting and frustrating for some students. Adding decorations that are inspirational and cheerful can help to improve the feel of the room, but bear in mind that many studênts need a peaceful and calm space to learn.

\section{Using the PAW: Classroom Décor}

Similar to the "Classroom Layout" section, the "Classroom Décor" section of the PAW encourages teachers to consider whether their décor is age-appropriate, calm, and inspirational for learning (see Figure 1). While it is somewhat subjective, this section was included on the PAW to help teachers review their classroom décor and consider changes that encourage student learning.

\section{Example-Ms. Nettles's Class}

This year, Ms. Nettles moved from teaching first- and second-grade resource to teaching a group of fourth and fifth graders with behavioral difficulties. Her current roster shows a group of eight boys. When looking through the decorations from her old classroom, she decided that her pale pink "Hang in there, kitty!" poster and her fluffy reading corner cushions were too "girly" and juvenile for her students. When she completed the PAW, she noted that these items, along with many others, were neither age-appropriate nor inspirational for her classroom. After evaluating her décor, Ms. Nettles purchased several sports posters showing popular athletes, and she made her own posters using inspirational quotes from historical sports figures such as Michael Jordan and Jackie Robinson. She also decided to have her students add to the décor on the first day of school by making "About Me" collages, using children's sports magazines and nature magazines. 


\section{Classroom Rules}

After arranging the desks in a classroom, the first thing posted on the walls should be the classroom rules. Clear rules that are understood by students and consistently implemented and monitored by the teacher are essential to a wellmanaged classroom. Rules communicate a teacher's expectations for desired classroom behavior (Emmer \& Evertson, 2009) and can foster a mutual respect among the teacher and students to effect a positive learning environment. Classroom rules are an important universal support to prepare students for appropriate classroom behavior (Fairbanks, Simonsen, \& Sugai, 2008; Simonsen, Sugai, \& Negron, 2008) and cut down on inappropriate behavior.

Classroom rules should be easy for students to understand and for teachers to monitor. Unclear rules can result in a lack of compliance by students (Trussell, 2008). This makes sense because if rules are not meaningful, how can students be expected to follow them? To this end, rules should be concise; in fact, shorter rules are often easier for students to remember. Teachers should establish three to five rules (Stewart et al., 1997; Trussell, 2008) that are broad enough to include all desired behavior (Simonsen, Fairbanks, et al., 2008). Rules should be stated positively, in terms of what a student should do rather than what a student should not do (Simonsen, Fairbanks, et al., 2008; Stewart et al., 1997; Trussell, 2008). They should be posted in the classroom and be clearly visible to all students and the teacher (Rademacher, Callahan, \& Pederson-Seelye, 1998; Simonsen, Sugai \& Negron, 2008; Trussell, 2008). Trussell noted that rules should be easy enough to understand so that all students are able to repeat the rules when asked. This is a good check for teachers to find out whether their classroom rules are clear enough and have been learned by students. In a study involving elementary teachers, Fairbanks et al. cited "Be respectful, responsible, and safe"(p. 49) as an example of an effective rule. The rule could be relevant to elementary, middle, and high school, as well as across special and general education settings, based on how the rule is defined and explained to students. The rule is clear, concise, and suitable for all situations.

\section{Teaching the Rules}

It is not enough to simply develop and post rules. Rules must be taught and explained to students (Simonsen, Fairbanks et al., 2008; Sprick et al., 1998). Effective classroom managers take time to teach rules explicitly and to tell students how and why to follow the rules (Rademacher et al., 1998). Examples and nonexamples can help students internalize rules and understand how they apply to various situations in and out of the classroom. Teachers should take the time to define what the rules look like in different contexts. For example, an elementary level teacher might teach "Be Safe" by showing students how to sit correctly versus incorrectly in their seats. A middle school teacher might explain that one aspect of the rule "Be Responsible" is arriving to class on time with the necessary materials. A high school math teacher might teach "Be Respectful" through a discussion of what constitutes respectful and disrespectful talk among peers in the classroom. Teachers should teach rules by using examples of how the rules apply to activities in which the students will engage during the class period or throughout the day. While it makes complete sense to teach the rules in the context of expected activities, teachers should also plan for the unexpected and teach students how the rules apply to assemblies, field trips, and fire drills. The more explicit a teacher can be during initial instruction on rules, the more prepared students are for appropriate behavior in the classroom.

Rules should be taught at the beginning of the year, starting on the first day of class. They should be reviewed throughout the first few weeks and again after extended school breaks. The addition of new students to the class during the middle of the school year offers an opportunity for teachers and students to "brush up" on their understanding of the classroom rules. Teachers need to implement and monitor the rules, while consistently delivering consequences for rule violations (Simonsen, Fairbanks, et al., 2008). Unpredictable implementation of the rules and consequences for rule violations can be confusing to students, make students wonder how important the rules are, and hinder the effectiveness of a management plan.

\section{Using the PAW: Rules}

The PAW is designed to help teachers evaluate the quality of their rules. On the form, teachers respond to several yes-no questions related to best practices in developing classroom rules, such as, "Are your rules posted in a visible area?" and, "Are your rules age appropriate, clear, concise, and written positively?" (see Rules in Figure 1). For any responses of "no," teachers are encouraged to modify their rules to make them more universally supportive.

\section{Example 1-Mr. Nguyen's Class}

Mr. Nguyen teaches sixth- and seventh-grade science. He knew that he needed high structure in his class and preferred this in his lab environment. He was also aware that he would be coteaching with a special education teacher during four inclusion periods this year, and he was somewhat nervous about the wide range of ability levels in his classes. When he completed the PAW, Mr. Nguyen realized that his 12 rules were mostly a list of "don'ts", such as, "Don't use lab equipment without permission," "Don't be late to class," and "Don't leave your lab station messy." Prompting on the PAW encouraged him to rewrite his rules as follows:

1. Be Prepared

2. Be Responsible

3. Be Respectful of Others and Property

4. Be Safe 
Mr. Nguyen realized that he probably could have shortened Rule 3 to simply state "Be Respectful," but he wanted to be very clear about respectful use of lab equipment. After writing a new list of rules and posting them at the front of the room and on each lab table, he found that he was actually looking forward to having fewer, more encompassing rules. Mr. Nguyen taught his rules during the first 2 days of class and reviewed the rules and how they related to lab experiments prior to each lab assignment.

\section{Example 2-Coach Carver}

Coach Carver teaches ninth and 11 th grade P.E. at Western High School, a rural county high school. She also coaches volleyball, softball, and girls' basketball. Coach Carver gets to know all of the students in the school because every ninthgrader takes her P.E. class. When she completed the PAW, she realized that she did not really have any clear rules, which might be contributing to the increasing number of students who seemed to be testing her limits and consequently sitting on the bench during P.E. Because she was starting from scratch, Coach Carver decided to write a set of rules that were relevant to P.E. and could carry over to her teams. Playing on the theme of the school mascot, she posted the following rules on a large banner in the gym: Western Wolf PACK: Pride, Ambition, Citizenship, Kindness. She explained what the acronym PACK meant, and, after explaining the rules through examples and nonexamples, she found that when a student or player was engaging in inappropriate behavior, she simply needed to say. "You're not being a part of the pack. Let's get it together." Most of the time, the individual would self-correct the behavior. Now that Coach Carver's diatribes on respectful behavior and acting like a "high schooler" were no longer necessary, she and her students were much more at ease, and the games and activities were much more fun.

\section{Classroom Routines}

A set of positive, easy-to-understand rules is essential to a well organized classroom, but students also need to be taught how to behave in various situations in order for the room to run smoothly. Classroom routines, also sometimes referred to as procedures (Rademacher et al., 1998; Trussell, 2008) or expectations for activities (Sprick et al., 1998), are specific steps that students take to accomplish actions in the classroom. These steps are designed to promote appropriate behavior (Trussell, 2008) by letting students know what they should do at all times in the classroom (Babkie, 2006). The intent behind establishing routines is to take the guesswork out of classroom behavior for students and replace it with very specific routines for common classroom activities, such as entering and leaving the classroom, answering questions, and accessing teacher help.

Establishing classroom routines is a component of primary PBS plans that is universally supportive of positive behavior (Simonsen, Sugai, \& Negron, 2008). Routines not only increase support for rule compliance (Rademacher et al., 1998), but also can increase student comfort with the rules (Babkie, 2006). Well-established classroom routines increase classroom efficiency, freeing up valuable instructional time that is often wasted on directing student behavior (Trussell, 2008). In fact, expert teachers have been found to do more to create and maintain routines in their classrooms than less expert teachers (Bohn, Roehrig, \& Pressley, 2004; Leinhardt, Weidman, \& Hammond, 1987). Bohn et al. (2004) found that in many cases the management systems of effective teachers are almost unnoticeable because they are so salient. In these classrooms, they found that teachers spent time at the outset of the school year teaching routines and practicing them with their students. Meaningful routines that fully disclose the expectations for student behavior during classroom activities decrease inappropriate behavior by encouraging appropriate classroom behavior.

A teacher should identify the core routines in the classroom as part of developing a management plan. One of the best ways to do this is for a teacher to visualize his or her class period (for middle and high school) or the full school day (for elementary school) and identify any times when teaching is interrupted, students need to move around the room, or students tend to get into trouble with peers or the teacher. Commonly, transition times, such as entering and leaving the classroom and switching from one activity to another, are more efficient when structured routines are in place. Other routines that help the organization of a classroom include answering questions and gaining the teacher's attention. A list of common routines is provided in Figure 2. The list provided there is a sample of routines, compiled to get teachers started in thinking about routines; it is by no means an exhaustive list. Teachers are encouraged to identify specific routines that are important and meaningful to them, their instructional goals, and their students.

- Entering and leaving the classroom

- Turning in assignments

- Organizing materials

- Lining up and walking down the hall

- Using classroom materials

- Gaining permission to go to the restroom

- Completing group work or independent work

- Gaining the teacher's attention

- Sharing materials with peers

- Preparing for homework assignments

- Heading papers

- Playing on the playground

- Sharpening pencils

FIGURE 2 Common Classroom Routines 
Effective classroom managers take the time to teach and practice routines (Bohn et al., 2004). They explain the routines, model the behaviors for their students, have students practice the routines, and praise students who are following the routines. This is important across elementary, middle, and high school levels. The teaching of routines should be suited to the type of classroom and the developmental level of the students and can include discussions, modeling by teacher or students, and role playing or practicing the routine. Regardless of teaching techniques used, explicitly teaching routines leaves nothing to chance and clarifies a teacher's expectations of behavior and actions in the classroom (Sprick et al., 1998).

\section{Using the PAW: Classroom Routines}

To encourage teachers to think about their classroom routines, the PAW asks them to list five routines that they would like all of their students to learn and follow in their classroom (see "Routines" in Figure 1). After listing routines, teachers are prompted to explain how they will teach each one. Although it is likely that teachers will have more than five routines for their classrooms, the PAW is intended to begin the process of mindfully developing routines in a manageable and feasible manner.

\section{Example 1-Mr. Jackson and Ms. Fisher's Class}

Mr. Jackson, a general education teacher, and Ms. Fisher, a special education teacher, coteach a third grade class. They have 24 students this year, 10 of whom have IEPs for learning or behavioral difficulties or both. The number of students and their varied learning needs, along with many other student and school risk factors, dictate a need for high structure in their classroom. After completing the PAW, Mr. Jackson and Ms. Fisher decided to begin their school year by teaching the following routines: (a) morning routine (entering the classroom, putting away materials, starting morning journal work), (b) restroom break, (c) speaking during lessons (raising hands and waiting to be called upon), (d) filing completed work, and (e) walking in the hallway. The teachers knew they would have to teach many other routines during the first month of school, but they decided this was a good place to start. They also considered their students and the best ways to teach the routines. In the end, Ms. Fisher and Mr. Jackson decided that a direct instructional approach with modeling and practice by the students would be best. They also decided on a method of rewarding students: Those who followed the routines would get extra stickers on a classwide behavior incentive chart.

\section{Example 2-Ms. Leftwitch's Class}

Ms. Leftwitch has had a sixth period Advisory and Study Hall added to her teaching load this year. During this period, she has fifteen 10th graders who are supposed to use the time to work on assignments from other classes and to get extra help in order to pass their state graduation exams. In general, these are students at risk for failing and dropping out of school. Ms. Leftwitch was told that she should support these students academically and engage them in discussions related to academic and social behavior. Since this was the first year teachers were being asked to teach an advisory and study hall, and Ms. Leftwitch was somewhat anxious about this, she welcomed the opportunity to use the PAW to plan for the class. She decided on these routines for her 10th graders: (a) entering the classroom, (b) working on assignments independently, (c) accessing help from the teacher, (d) what to do when all of your work is complete, and (e) participating in class discussions. Because she taught high school students and the nature of the class was somewhat casual, Ms. Leftwitch decided to teach these routines by explaining each routine and having the students generate examples in a discussion format. She planned to reinforce appropriate routines by providing student praise in a noninvasive and age-appropriate manner. In other words, she planned to praise students quietly, without embarrassing them or making them feel "uncool."

\section{Maintaining and Monitoring Behavior}

At the beginning of the year, teachers expect to rearrange their rooms and spend time teaching rules and routines to students, which makes it a natural time to prepare and implement a management plan. Unfortunately, many teachers stop there. Expert teachers work to maintain their management plans throughout the year (Bohn et al., 2004); still, some students require more than the universal level of support provided by even the best classroom managers.

An effective management plan does not run on its own. Like an automobile, it needs regular maintenance to run at peak performance. To maintain a management plan, students need their teachers' feedback on their behavior. Teachers should praise appropriate behavior and provide logical negative consequences for inappropriate behavior (Rademacher et al., 1998). Praise should describe the behavior that was performed and should be delivered directly following the desired behavior. For example, stating, "I appreciate everyone coming to the circle quickly and quietly," is much more effective than saying, "Good job," after all students have been seated. The former statement offers praise and also draws attention to what students did correctly. Praise should be delivered in a way that is suitable to the students' age and developmental level. A big smile and, "Wow, it's great that you completed your assignment on time. Excellent work!" might be received well by a second grader, but an eighth grader would likely be embarrassed by such a vivacious display of praise.

Feedback on inappropriate student behavior is also necessary to maintain a universally supportive management plan. Students need to know when they are not following the class rules and procedures, and they should know the consequences of their actions. When informing students of their misbehavior, teachers need to be respectful of their students 
(Babkie, 2006) and take care not to shame or embarrass them in front of their peers. Maintaining a ratio of four positive comments for each negative comment is a good rule of thumb when faced with a more challenging student (Trussell, 2008). This keeps the dialogue with the student constructive and encouraging rather than pessimistic and off-putting. In general, however, teachers need to correct students when they are not following the rules and routines in addition to telling them when they are doing things right.

Another way to maintain a plan is to review components of the plan and make changes as needed. Students get out of practice after extended breaks from school and need a review of the rules and routines. Also, classroom dynamics change throughout the year, and problem areas arise. Taking the time to establish new routines and even increase the level of structure in a classroom is sometimes necessary. Classroom management plans are not set in stone and should be modified to fit current situations. If something is not working in a classroom, the teacher should review the whole plan and change it to suit class needs.

Unfortunately, even the best plan will not work for all students (Fairbanks et al., 2008). A universally supportive management plan is the basis of PBS and will be sufficient for most students, but some students will require more targeted interventions, referred to as secondary and tertiary supports (Simonsen, Sugai, \& Horner, 2008). If a student is not responding to a well-designed and consistently implemented management plan, further information on the student behavior should be used to develop more supportive management structures for that student.

Data collection is an integral component of a management plan to allow teachers to keep track of student successes and behavioral infractions. If a student is struggling in the classroom, the teacher can evaluate data to identify behavioral patterns by activity, day of the week, and time of day (Babkie, 2006). Data can also be used to identify groups of students who are having more difficulties than average, as well as the frequency and type of rule infractions committed by these students. There are many ways to collect data on student behavior. These can be as unstructured as anecdotal observations, notes, and logs of rule infractions, or as specific and structured as calculation of numbers of office referrals or individualized rule-based point systems. Teachers should identify a data collection method that they will use and that will provide the necessary documentation to trigger a secondary intervention if it is needed.

No teacher is expected to be able to handle all behavioral difficulties in the classroom without assistance. Even the most experienced and effective classroom manager occasionally runs into a student who needs more targeted support than the teacher can give. In this case, the teacher needs to know when and whom to ask for help. After a teacher has reviewed the classwide plan, increased classroom structure, retaught rules and expectations, and collected data on behavior, it is time to access support from another school professional. Sources of behavioral support vary by district and school. Behavioral support may be accessed from school counselors, principals, special education teachers, school social workers, behavior analysts, and even parents. Teachers should always know to whom they can turn for support regarding student behavior.

\section{Using the PAW: Maintaining and Monitoring Behavior}

This section of the PAW (see Figure 1, Maintaining and Monitoring Behavior) is designed to initiate teachers' consideration of the ways they maintain student behavior through praise. It also prompts teachers to think about how they collect, or will collect, data on problem behaviors. Teachers are also encouraged to identify a source of support for working with problem behaviors in their classroom before difficulties arise.

\section{Example 1-Ms. Elsner's Class}

Ms. Elsner is the 10th grade resource teacher for her school. She supports students in her classroom and in inclusive settings. When completing the PAW, Ms. Elsner was very surprised to find that she had very few good strategies for praising appropriate behavior demonstrated by her students. In the past, she had stopped using public praise statements such as, "I love how you are all working so hard," because a student once responded with the comment, "Why are you talking to us like we are babies?" Ms. Elsner was so embarrassed by the student's comment that she had stopped praising altogether. As she completed the PAW, she thought of three ways she could praise her high school students: (1) nonverbal cues, such as pointing at an answer on the paper and giving a thumbs-up sign or a quiet statement, such as, "Nice"; (2) private, one-on-one commendation of a student at the teacher's desk after class or written on an assignment; and (3) restating a student's answer followed by a comment such as, "You've got it!" or, "Right," delivered without excessive emotion.

\section{Example 2-Ms. McMillan}

Ms. McMillan teaches music to all of the students in her elementary school. She sees students in special education with their grade-level groups and works well with most students. Ms. McMillan knows that she really struggles with students who have attention and behavioral difficulties, and she wants to set up a good management plan for her students this year. She understands the importance of behavior-specific praise and provides plenty of enthusiastic praise in her classrooms. Ms. McMillan is somewhat concerned about keeping track of student misbehavior. Last year, she sent the problem students out of the room, and she was frustrated when the classroom and special education teachers asked her why students were sent out. She knows that she needs to keep track of misbehavior, but she also knows that, with over 400 
students a week in her classes, she needs to have a very easy to use method of evaluating behavior. Ms. McMillan decided to keep a behavioral gradebook. She listed all of her students by class and noted behavioral infractions at the end of each class period. This allowed her to see patterns of behavior by day of the week, grade, and student. Ms. McMillan found this system particularly helpful when she approached the behavioral support specialist assigned to her school and asked for ideas to help with a class of especially rowdy third graders. The behavior support specialist was able to look at the behavioral patterns and at Ms. McMillan's notes and then give the teacher suggestions on how to bolster classwide universal supports for this particular group of third graders.

\section{CONCLUSION}

An effective and universally supportive classroom management plan is fundamental to establishing an effective learning environment for all students. Heterogeneous classrooms are increasingly common, thereby expanding the depth of universal supports that need to be in place. Classrooms need to function to serve a wide range of students' academic, social, and behavioral abilities. This article presents a worksheet to guide teachers through the process of establishing and evaluating a management plan suited to their students and their classroom. Hopefully, information in this article will help teachers increase their confidence in classroom management and will aid administrators in recognizing the components of universally supportive management plans and inidentifying the common needs of their faculties. When put in place at the beginning of the year, classroom management plans can help teachers create supportive environments that allow teachers to teach and allow all students to learn.

\section{REFERENCES}

Babkie, A. M. (2006). 20 ways to ... Be proactive in managing classroom behavior. Intervention in School and Clinic, 41, 184-187.

Blase, J. L. (1986). A qualitative analysis of teacher stress: Consequences for performance. American Educational Research Journal, 23, 13-40.

Bohn, C. M., Roehrig, A. D., \& Pressley, M. (2004). The first days of school in the classrooms of two more effective and four less effective primary grades teachers. Elementary School Journal, 104, 269-287.

Bushaw, W. J., \& Gallup, A. (2008). The 40th annual Phi Delta Kappa/ Gallup poll of the public's attitudes toward the public schools. Phi Delta Kappan, 90, 9-20.

Cipani, E. C. (2007). Classroom Management for All Teachers: Plans for Evidence-Based Practice. Upper Saddle River, NJ: Pearson.

Connelly, V., \& Graham, S. (2009). Student teaching and teacher attrition in special education. Teacher Education and Special Education, 32, 257-269.

Emmer, E. T., \& Evertson, C. M. (2009). Classroom Management for Middle and High School Teachers. Upper Saddle River, NJ: Pearson.

Emmer, E. T., \& Stough, L. M. (2001). Classroom management: A critical part of educational psychology, with implications for teacher education. Educational Psychologist, 36(2), 103-112.

Evertson, C. M., Emmer, E. T., \& Worsham, M. E. (2006). Classroom management for middle and high school teachers, Boston: Allyn \& Bacon.
Fairbanks, S., Simonsen, B., \& Sugai, G. (2008). Classwide secondary and tertiary tier practices and systems. Teaching Exceptional Children, $40(6), 44-52$.

Harrell, P., Leavell, A., van Tassell, F., \& McKee, K. (2004). No teacher left behind: Results of a five-year study of teacher attrition. Action in Teacher Education, 26(2), 47-59.

Ingersoll, R. M., \& Smith, T. M. (2003). The wrong solution to the teacher shortage. Educational Leadership, 60(8), 30-33.

Judd, J. (1995). Let's all play musical chairs. The Independent, Independent News \& Media. Retrieved from http://license.icopyright.net/user/view FreeUse.act?fuid=NDIwNDk0Mg\%3D\%3D

Leinhardt, G., Weidman, C., \& Hammond, K. M. (1987). Introduction and integration of classroom routines by expert teachers. Curriculum Inquiry, 17, 135-176.

LePage, P., Darling-Hammond, L., Akar, H., Gutierrez, C., Jenkins-Gunn, E., \& Rosebrock, K. (2005). Classroom management. In L. DarlingHammond \& J. Bransford (Eds.), Preparing Teachers for a Changing World: What Teachers Should Learn and Be Able to Do (pp. 327-357). San Francisco: Jossey-Bass.

McLeskey, J., Tyler, N., \& Saunders Flippin, S. (2004). The supply and demand for special education teachers: A review of research regarding the chronic shortage of special education teachers. The Journal of Special Education, 38, 5-21.

Oliver, R. M., \& Reschly, D. J. (2007). Effective Classroom Management: Teacher Preparation and Professional Development. Retrieved from http://www.tqsource.org/topics/effectiveClassroom Management.pdf

Punch, K., \& Tuettemann, L. (1990). Correlates of psychological distress among secondary school teachers. British Educational Research Journal, 16(4), 369-383.

Rademacher, J. A., Callahan, K., \& Pederson-Seelye, V. A. (1998). How do your classroom rules measure up? Guidelines for developing an effective rule management routine. Intervention in School and Clinic, 33, 284-289.

Simonsen, B., Fairbanks, S., Brieschs, A., Myers, D., \& Sugai, G. (2008). Evidence-based practices in classroom management: Considerations for research to practice. Education and Treatment of Children, 31 , 351-380.

Simonsen, B., Sugai, G., \& Negron, M. (2008). School-wide positive behavior support: Primary systems and practices. Teaching Exceptional Children, 40, 32-40.

Sprick, R. S., Garrison, M., \& Howard, L. M. (1998). CHAMPS: A proactive and positive approach to classroom management. Longmont, $\mathrm{CO}$ : Sopris West.

Stewart, S. C., Evans, W. H., Witt, W. H., \& Kaczynski, D. J. (1997). Setting the stage for success: Assessing the instructional environment. Preventing School Failure, 41, 53-56.

Sugai, G. \& Homer, R. (2002). The evolution of discipline practices: School-wide positive behavior supports. Child \& Family Therapy, 24, 23-50.

Trussell, R. P. (2008). Classroom universals to prevent problem behavior. Intervention in School and Clinic, 43, 179-185.

U.S. Department of Education. (2001). Twenty-third annual report to Congress on the implementation of the education of the handicapped act. Washington, DC: U.S. Government Printing Office.

Veenman, S. (1984). Perceived problems of beginning teachers. Review of Educational Research, 54, 143-178.

Webster-Stratton, C., \& Taylor, T. (2001). Nipping early risk factors in the bud: Preventing substance abuse, delinquency, and violence in adolescence through interventions targeted at young children (0-8 years). Prevention Science, 2, 165-192.

Wilson, B., Ireton, E., \& Wood, J. A. (1997). Beginning teacher fears. Education, $117(3), 396-402$. 